\title{
Executive Control Signals in Orbitofrontal Cortex during Response Inhibition
}

\author{
Daniel W. Bryden ${ }^{1,2}$ and Matthew R. Roesch ${ }^{1,2}$ \\ ${ }^{1}$ Department of Psychology, and ${ }^{2}$ Program in Neuroscience and Cognitive Science, University of Maryland, College Park, Maryland 20742
}

Orbitofrontal cortex $(\mathrm{OFC})$ lesions produce deficits in response inhibition and imaging studies suggest that activity in $\mathrm{OFC}$ is stronger on trials that require suppression of behavior, yet few studies have examined neural correlates at the single-unit level in a behavioral task that probes response inhibition without varying other factors, such as anticipated outcomes. Here we recorded from single neurons in lateral OFC in a task that required animals in the minority of trials to STOP or inhibit an ongoing movement and respond in the opposite direction. We found that population and single-unit firing was modulated primarily by response direction and movement speed, and that very few OFC neurons exhibited a response independent inhibition signal. Remarkably, the strength of the directional signal was not diminished on STOP trials and was actually stronger on STOP trials during conflict adaptation. Finally, directional signals were stronger during sessions in which rats had the most difficulty inhibiting behavior. These results suggest that "inhibition" deficits observed with OFC interference studies reflect deficits unrelated to signaling the need to inhibit behavior, but instead support a role for OFC in executive functions related to dissociating between two perceptually similar actions during response conflict.

Key words: conflict; inhibition; orbitofrontal; rat; single unit; stop signal

\section{Introduction}

The ability to inhibit unwanted actions is necessary for everyday behavior. Research has suggested that orbitofrontal cortex (OFC) acts as a critical frontal area that informs downstream regions of the need to suppress behavior. Evidence for this arose as damage to OFC was shown to promote disinhibition operationalized as perseveration during extinction tasks (Charles, 1969), reduced reversal ability (McEnaney and Butter, 1969; Iversen and Mishkin, 1970; Jones and Mishkin, 1972; Rolls et al., 1994; Meunier et al., 1997; Chudasama and Robbins, 2003; Fellows and Farah, 2003; McAlonan and Brown, 2003; Schoenbaum et al., 2003; Hornak et al., 2004; Izquierdo et al., 2004; Bissonette et al., 2008), impulsive choice in both delay discounting (Mobini et al., 2002; Zeeb et al., 2010) and stop tasks (Eagle et al., 2008; Majid et al., 2013), and impaired gambling behavior (Bechara et al., 1999; Zeeb and Winstanley, 2011). Many of these studies suggest that OFC provides a type of inhibitory signal that overrides or dampens behavioral responding when such control is necessary for accurate performance. Indeed, imaging studies have shown heightened BOLD signals generating from $\mathrm{OFC}$ on trials that require participants to inhibit behavior (Casey et al., 1997; Horn et al., 2003; Rubia et al., 2005; Chikazoe et al., 2009; Majid et al., 2013).

\footnotetext{
Received Aug. 27, 2014; revised Jan. 23, 2015; accepted Jan. 28, 2015.

Author contributions: D.W.B. and M.R.R. designed research; D.W.B. performed research; D.W.B. and M.R.R. analyzed data; D.W.B. and M.R.R. wrote the paper.

This work was supported by a Grant from the NIDA (R01DA031695; M.R.R.). We thank Juliet Aiken and Jeffrey

Chrabaszcz from Design and Statistics Analysis Laboratory for advice regarding multiple regression analyses.

The authors declare no competing financial interests.

Correspondence should be addressed to either Dr Matthew Roesch or Daniel Bryden, University of Maryland, College Park, MD 20742. E-mail: mroesch@umd.edu or dbryden@umd.edu.

DOI:10.1523/JNEUROSCI.3587-14.2015

Copyright $\odot 2015$ the authors $\quad 0270-6474 / 15 / 353903-12 \$ 15.00 / 0$
}

Over the past decade, the theory that inhibitory function is causally linked to OFC has lost some ground due to data revealing that OFC lesioned animals can exhibit certain forms of inhibitory restraint as well as healthy control animals (Kheramin et al., 2003; Winstanley et al., 2004; Chudasama et al., 2007; Swick et al., 2008). For example, rats with OFC lesions can discontinue responding to stimuli that unpredictably lead to punishment during discrimination learning (Schoenbaum et al., 2003) or suddenly predict no reward during set-shifting (McAlonan and Brown, 2003; Ghods-Sharifi et al., 2008).

With the abundance of attention OFC has received during the past few decades, it comes as a surprise that there have been few recordings from OFC during performance of a task that independently probes response inhibition. Most tasks vary both the need to inhibit behavior and aspects related to expected outcomes. To address these issues we recorded from OFC in our rodent variant of the stop-signal task (Bryden et al., 2012). In the majority of trials $(80 \%)$, rats were instructed to respond (GO) to a directional cuelight. On the remaining $20 \%$ of trials rats had to inhibit their initiated response and redirect movement in the opposite direction to achieve reward (STOP trials). We show that activity in OFC does not carry a pure nondirectional inhibitory signal when the animal successfully inhibits a behavioral response and that directional signals are enhanced on STOP trials following STOP trials, consistent with conflict adaptation (Botvinick et al., 2001; Mansouri et al., 2014).

\section{Materials and Methods}

Subjects. Five male Long-Evans rats were obtained at 175-200 g from Charles River Laboratories. Rats were tested at the University of Maryland in accordance with NIH and IACUC guidelines.

Surgical procedures and histology. Surgical procedures followed guidelines for aseptic technique. Electrodes were manufactured and implanted 
A
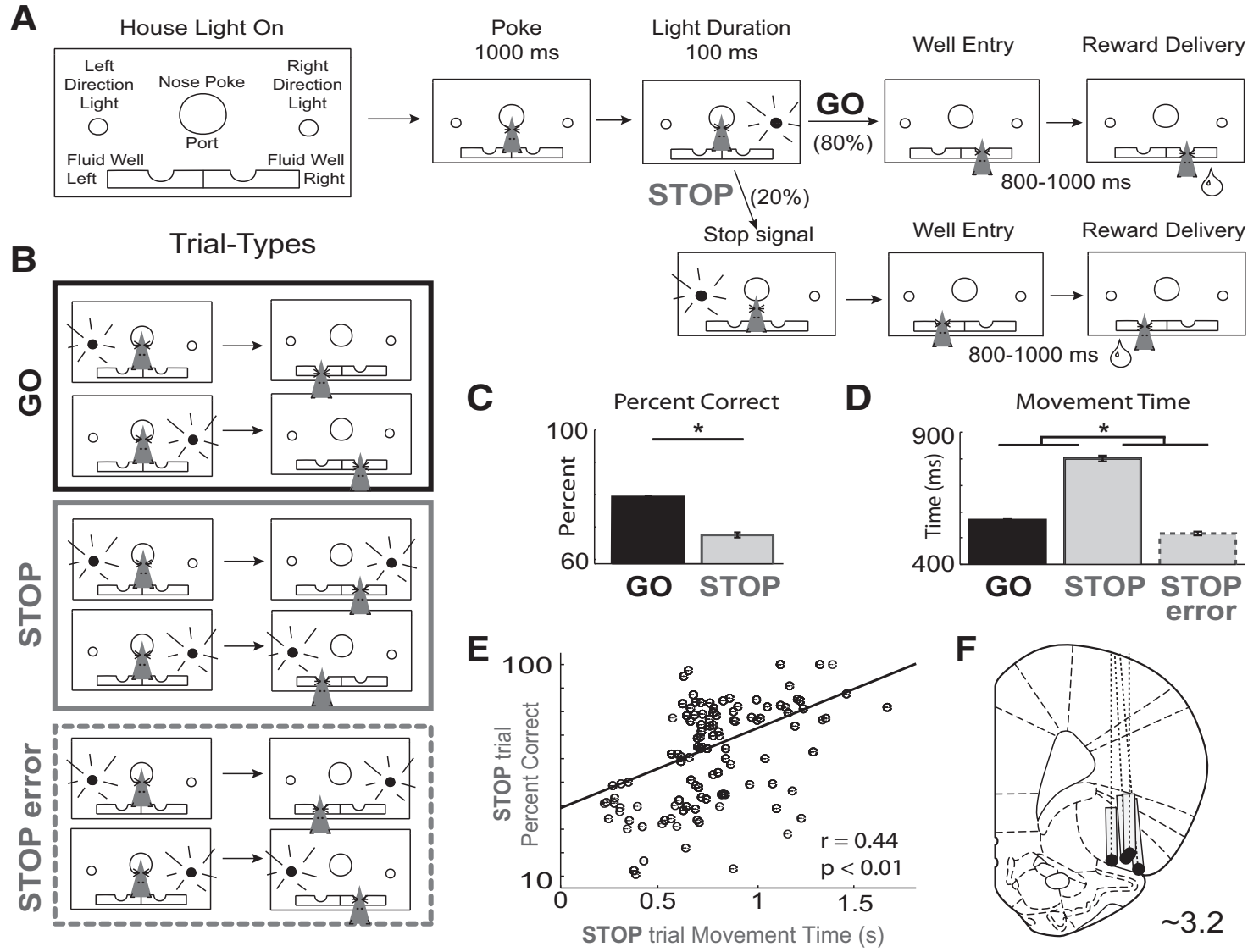

Figure 1. Stop-signal task and behavior. $A$, House lights instructed rats that nose-poke into the central port would initiate a trial. Rats were required to nose-poke and remain in the port for 1000 $\mathrm{ms}$ before one of the two directional lights (left or right) illuminated for $100 \mathrm{~ms}$. The cue-light disclosed the response direction in which the animal could retrieve fluid reward. $0 \mathrm{n} 20 \%$ of all trials, simultaneous with port exit, the light opposite the first illuminated to instruct the rat to inhibit the current action and redirect behavior to the corresponding well under the second light. With the selection of the correct fluid well, reward was delivered after an $800-1000 \mathrm{~ms}$ delay. B, Two conditions by two directions yields four possible trial-types (G0 and STOP). Errors are unrewarded. C, Percentage of correct trials ( \pm SEM) for GO and STOP trials. D, Movement time in milliseconds ( \pm SEM) for GO trials, STOP trials, and STOP errors defined as the latency from port exit to fluid well entry. Asterisks indicate planned comparisons revealing statistically significant differences ( $t$ test, $p<0.05$ ). $\boldsymbol{E}$, Speed-accuracy tradeoff. Percentage correct on STOP trials for every session plotted against average movement time (port exit to well entry). $\boldsymbol{F}$, Location of recording sites. Gray boxes mark extent of the recording locations. Black dots mark the bottom of the recording tract. Sessions from one rat (data not shown) were terminated early due to technical issues. Data from this animal's two neurons were not significantly modulated by the task and were excluded from further analysis.

as in prior recording experiments (Bryden et al., 2011; Burton et al., 2014). Rats were implanted with a drivable bundle of ten $25-\mu \mathrm{m}-$ diameter FeNiCr wires (Stablohm 675, California Fine Wire) in the left or right hemisphere dorsal to lateral OFC $[n=5$ rats; $3 \mathrm{~mm}$ anterior to bregma, $3.2 \mathrm{~mm}$ left $(n=2)$ or right $(n=3)$ of midline, and $4 \mathrm{~mm}$ ventral to the brain surface]. Immediately before implantation, these wires were freshly cut with surgical scissors to extend $\sim 1 \mathrm{~mm}$ beyond the cannula and electroplated with platinum $\left(\mathrm{H}_{2} \mathrm{PtCl}_{6}\right.$, Aldrich) to an impedance of $\sim 300 \mathrm{kOhms}$. Cephalexin (15 mg/kg p.o.) was administered twice daily for 2 weeks postoperatively to prevent infection.

Behavioral task. Recording was conducted in aluminum chambers $\sim 18$ inch on each side with downward sloping walls narrowing to an area of $12 \times 12$ inches at the bottom. On one wall, a central odor port was located above two adjacent fluid wells. Directional lights were located next to the fluid wells. House lights were located above the panel. Task control was implemented via computer. Port entry and licking was monitored by disruption of photobeams.

The basic design of a trial is illustrated in Figure $1 A, B$. Each trial began by illumination of house lights that instructed the rat to nose poke into the central port. Nose poking initiated a $1000 \mathrm{~ms}$ pre-cue delay period during which the rat was required to stay inside the central port. At the end of this delay, a directional light to the animal's left or right was flashed for $100 \mathrm{~ms}$. The trial was aborted if the rat exited the port at any time before offset of the directional cue light. On $80 \%$ of trials, presentation of either the left or right light signaled the direction in which the animal could respond to obtain sucrose reward in the corresponding fluid well below. These are referred to as GO trials. On 20\% of trials, simultaneous with the rat exiting the nose-port, the light opposite to the location of the originally cued direction turned on and remained illuminated until the behavioral response was made. These STOP trials were randomly interleaved with GO trials. Rats were required to inhibit the movement signaled by the first light and respond in the direction of the second light. After correct responses, rats were required to remain in the fluid well for a variable period between 800 and $1000 \mathrm{~ms}$ (pre-fluid delay) before reward delivery ( $10 \%$ sucrose solution). Trials were presented in a pseudorandom sequence such that left and right trials were presented in equal numbers ( \pm 1 per 250 trials). The intertrial interval was $4 \mathrm{~s}$. The time necessary to stop and redirect behavior (stop change reaction time; SCRT) on STOP trials was computed by calculating the difference between average correct STOP trial movement time and average correct GO trial movement time. Movement time is calculated by the latency between port exit and well entry.

Single-unit recording. Procedures were the same as described previously (Bryden et al., 2011). Wires were screened for activity daily; if no activity was detected, the rat was removed, and the electrode assembly was advanced 40 or $80 \mu \mathrm{m}$. Otherwise, active wires were selected to be recorded, a session was conducted, and the electrode was advanced 40 or $80 \mu \mathrm{m}$ to obtain recordings from new cells. Neural activity was recorded using four identical Plexon Multichannel Acquisition Processor systems, interfaced with training chambers. Signals from the electrode wires were amplified $20 \times$ by an op-amp headstage, located on the electrode array. Immediately outside of the training chamber, the signals were passed 
A

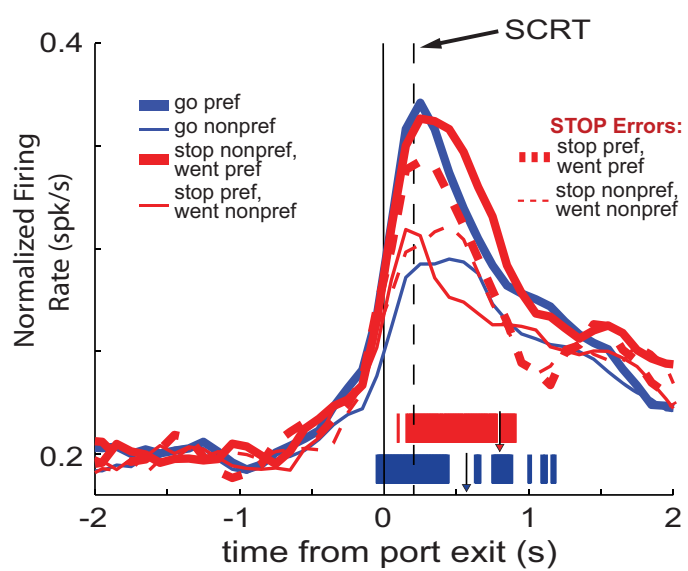

B

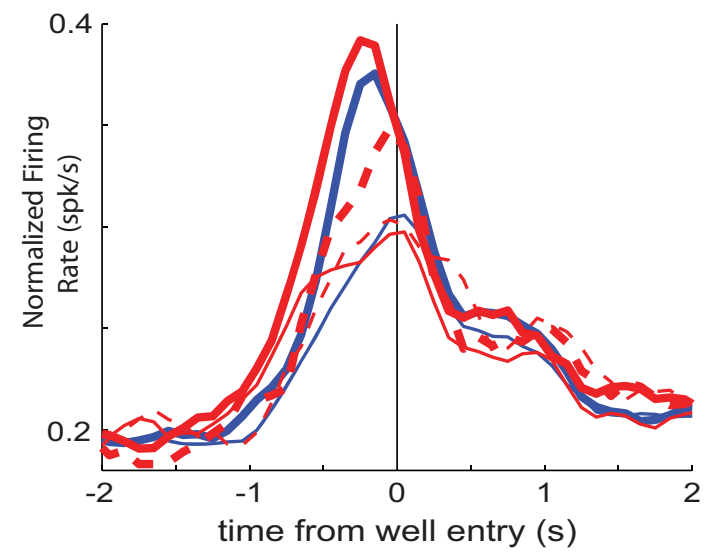

* \begin{tabular}{|c|c|}
\hline $\mathrm{ns}$ & $*$ \\
\hline
\end{tabular}

C

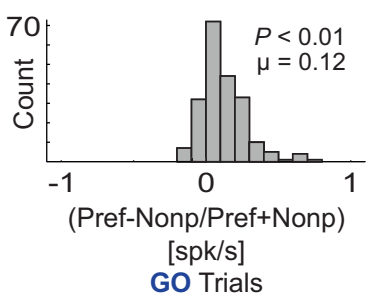

D

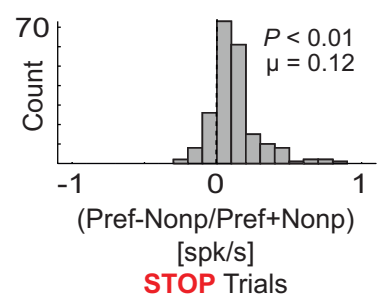

E

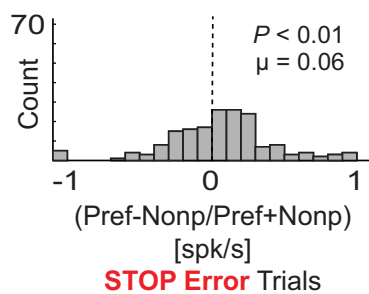

Figure 2. Impact of direction and trial-type on increasing-type OFC neurons. $\boldsymbol{A}, \boldsymbol{B}$, Population histograms of all OFC neurons that fired significantly above baseline $(n=209)$. Firing rate is normalized to the strongest elicited firing frequency. Direction preference is based on the response direction that elicited the highest firing rate for both correct STOP and correct $\mathrm{GO}$ trials during the response epoch. Preference is specified for each cell individually (thick lines represent preferred direction, thin lines represent nonpreferred direction). Red lines refer to STOP trials and blue lines refer to $\mathrm{GO}$ trials. Solid lines represent correct trials; dashed lines represent incorrect trials. Activity is aligned to port exit $(\boldsymbol{A})$ and fluid-well entry $(\boldsymbol{B})$, respectively. Vertical dashed line indicates the average SCRT for these sessions marked at $233 \mathrm{~ms}$. Tick marks represent time points of statistically significant direction firing (preferred vs nonpreferred direction) for G0 trials (blue) or STOP trials (red) analyzed by sliding a $100 \mathrm{~ms}$ window every $10 \mathrm{~ms}$ ( $t$ test, $p<0.01$ ). Although each tick mark signifies statistical difference for a $100 \mathrm{~ms}$ epoch, tick width is $10 \mathrm{~ms}$ for the purpose of presentational detail. Individual arrows depict average movement time for STOP trials (red arrowhead; $806 \mathrm{~ms}$ ) and G0 trials (blue arrowhead; $573 \mathrm{~ms}$ ) for the analyzed sessions. Legend: For red lines, the top-most text refers to the $\mathrm{GO}$ direction (e.g., "stop nonpref" = animal was cued to inhibit responding to the nonpreferred direction). The bottom-most text refers to the animal's ultimate response direction. $\boldsymbol{C}-\boldsymbol{E}$, Direction indices which took firing in the preferred direction, subtracted firing in the nonpreferred direction, and divided the difference by the sum of firing in both directions (preferrednonpreferred)/(preferred + nonpreferred) for each cell. This firing analysis is taken during the response epoch and is separate for correct GO trials (C), correct STOP trials (D), and STOP errors (E). Distributions are determined to be significantly different from zero via Wilcoxon $(p<0.05)$. Asterisks signify whether two distributions are significantly different from one another via Wilcoxon $(p<0.05)$.

through a differential preamplifier (Plexon, PBX2/16sp-r-G50/16fpG50), where single-unit signals were amplified $50 \times$ and filtered at $150-$ $9000 \mathrm{~Hz}$. The single-unit signals were then sent to the Multichannel Acquisition Processor box, where they were further filtered at 250-8000 $\mathrm{Hz}$, digitized at $40 \mathrm{kHz}$ and amplified at $1-32 \times$. Waveforms $(>2.5: 1$ signal-to-noise) were extracted from active channels and recorded to disk by an associated workstation with event timestamps from the behavior computer. Waveforms were not inverted before data analysis.

Data analysis. Units were sorted using Offline Sorter software from Plexon, using a template matching algorithm. Sorted files were then processed in Neuroexplorer to extract unit timestamps and relevant event markers. These data were subsequently analyzed in MATLAB. Baseline firing was taken during a $1 \mathrm{~s}$ epoch starting $2 \mathrm{~s}$ before trial initiation (nose-poke). This baseline epoch was used exclusively to classify neurons as task-related (i.e., increasing- or decreasing-type) and was chosen as a period where rats are relatively stationary, yet prepared to initiate the upcoming trial. For the majority of the analyses, activity was examined during the period between nose poke exit and well entry (termed "response epoch"), while the movement was being made and/or cancelled. Activity in population histograms (Figs. 2, 3,5,6 A, B, 8A, C) was normalized by dividing by the maximal firing rate of each neuron. All statistical procedures were executed using raw firing rates. Wilcoxon tests were used to measure significant shifts from zero in distribution plots $(p<0.05)$. T tests were used to measure within cell differences in firing rates and behavioral data where indicated $(p<0.05)$. Chi-square tests $(p<0.05)$ were used to determine whether counts of cells were different from zero. Significant direction signaling, as a function of time, was determined using a sliding window analysis. For STOP and GO trials independently, activity between the preferred and nonpreferred directions was compared in $100 \mathrm{~ms}$ epochs, which slid $10 \mathrm{~ms}$ after each iteration. To complement these analyses, we used least-squares multiple regression as a means to determine the number of cells where firing rate was significantly correlated with either the trial-type (STOP/GO), movement time, and/or response direction parameters when variance for the two remaining factors was accounted for. To achieve this, we ran the following multiple model for each individual cell:

$$
Y=\beta_{0}+\beta_{1} \text { Movement Time }+\beta_{2} \text { Trial Type }+\beta_{3} \text { Direction, }
$$

where $Y=$ firing rate (spikes/s) during the response epoch, Movement Time $=$ latency between unpoke and well entry, Direction $=$ coded as $(-1=$ ipsilateral $)(1=$ contralateral $)$, and Trial Type $=\operatorname{coded}$ as $(-1=$ GO) $(1=$ STOP $)$.

To determine the significance for each predictor as a function of firing rate during the response epoch, we computed the unique variance of each individual parameter and divided it by the variance unaccounted for 
A

\section{FAST Movement Times}

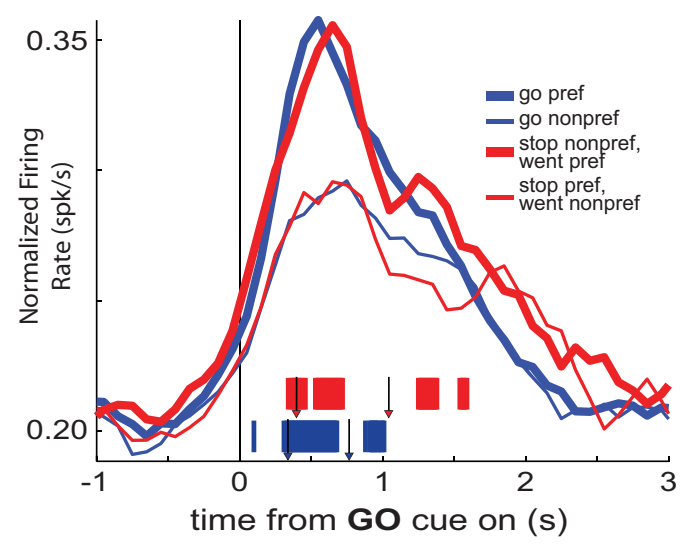

C

FAST Movement Times

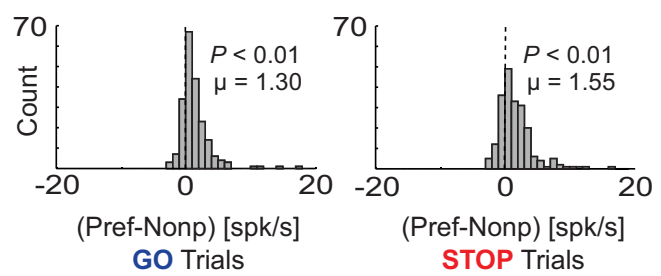

B

\section{SLOW Movement Times}

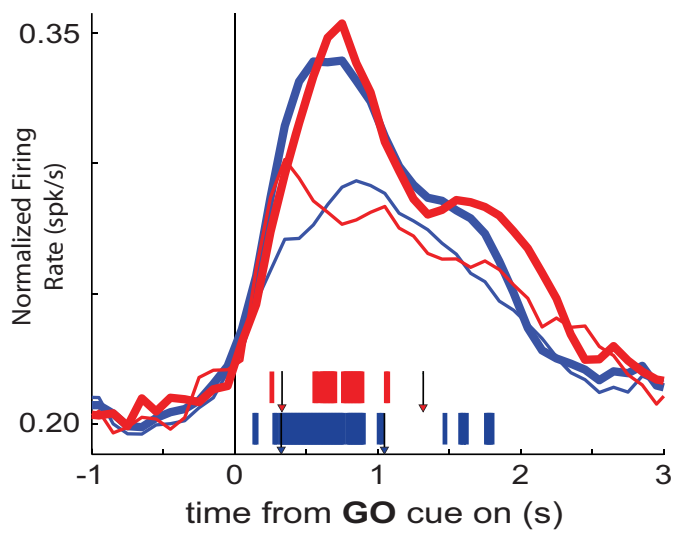

D

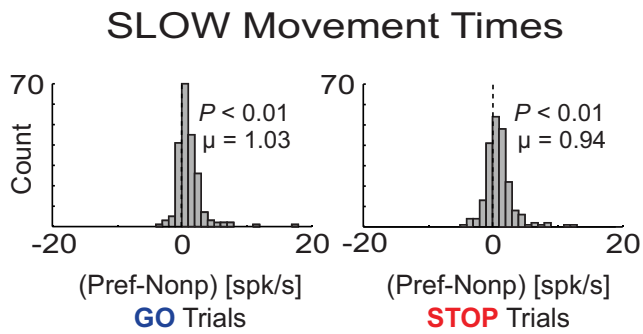

Figure 3. Firing of increasing-type OFC neurons was related to movement time. $\boldsymbol{A}, \boldsymbol{B}$, Population histograms of all increasing-type 0FC neurons ( $n=209$ ). Movement time median split for each direction in each trial-type yields one histogram of FAST trials $(\boldsymbol{A})$ and one of SLOW trials $(\boldsymbol{B})$ each aligned on G0 cue onset. Tick marks represent time points of statistically significant direction firing (preferred vs nonpreferred direction) for G0 trials (blue) or STOP trials (red) analyzed by sliding a 100 ms window every 10 ms ( $t$ test, $p<0.01$ ). Left-most arrows depict average latency to unpoke after G0 cue illumination for STOP trials (red arrowheads; FAST $=397 \mathrm{~ms} ;$ SLOW $=330 \mathrm{~ms}$ ) and G0 trials (blue arrowheads; FAST $=338 \mathrm{~ms} ;$ SLOW $=326 \mathrm{~ms}$ ) for the analyzed sessions. Right-most arrows depict average latency to well entry after G0 cue illumination for STOP trials (red arrowheads; FAST = $1043 \mathrm{~ms} ;$ SLOW = $1318 \mathrm{~ms}$ ) and G0 trials (blue arrowheads; FAST = 766 ms; SLOW = $1047 \mathrm{~ms}$ ) for the analyzed sessions. C, Direction index distributions calculated without dividing by the sum of preferred and nonpreferred activity. This procedure deviates slightly from that of Figures 2 and 4 due to more frequent extreme difference scores after the number of trials for each distribution was split in half. Direction distributions encompass all FAST movements during $\mathrm{GO}$ trials (left) and STOP trials (right). D, Direction index distributions for SLOW trials. Other conventions as in $\boldsymbol{C}$. Distributions are determined to be significantly different from zero via Wilcoxon ( $p<0.05$ ). Distributions are determined to be significantly different from one another via Wilcoxon $(p<0.05)$.

when each respective parameter was not included in the model (partial $\left.r^{2}\right)$. Significance of each partial $r^{2}$ was recorded along with the valence of the $\beta$-value. Counts of positively and negatively correlated cells were compared via binomial sign test $(p<0.05)$. For clarity, it was possible that a single cell could show a significant partial $r^{2}$ for all three parameters. Each parameter was calculated in the same manner regardless of whether a neuron was an increasing- or decreasing-type cell. Absolute value of the firing rate was never used.

\section{Results}

Rats were trained on a task in which spatially opposite (left and right) cue lights instructed the direction of the behavioral response necessary to obtain fluid reward. The task is illustrated in Figure $1 A, B$. Illumination of the house lights signaled the start of each trial. Rats could then initiate a trial by nose-poking into the central port (Fig. 1A). After a $1000 \mathrm{~ms}$ delay period where the rat was required to stay in the nose-port, a directional cue light to the left or right of the nose-port flashed $(100 \mathrm{~ms})$ indicating the direction in which the animal must respond to receive reward. These trials will be referred to as GO trials and occurred on a random $80 \%$ of all trials. The remaining $20 \%$ of trials began in the same manner but, simultaneous with withdrawal from the noseport, a second cue light illuminated opposite the first, instructing the animal to stop its initiated movement and respond in the opposite direction (the well corresponding to the second light).
These trials will be referred to as "STOP-change" or "STOP" trials for short. The STOP cue was illuminated only after the initial movement had commenced (i.e., simultaneous with port exit), thus we are examining the rats' ability to inhibit a prepotent and programmed motor behavior. For each trial, animals were required to remain in the reward well for a random duration between 800 and $1000 \mathrm{~ms}$ before receiving reward. There were a total of four different trial-types: GO-left, GO-right, STOP-leftGO-right, and STOP-right-GO-left; however, for the remainder of the paper, response direction (i.e., left and right) will be referenced to the hemisphere of the recording site (contralateral or ipsilateral) or the directional preference of each individual neuron (preferred or nonpreferred).

On STOP trials rats exhibited significantly slower movement speeds (latency between port exit and well entry) and reduced accuracy compared with GO trials (Fig. 1C,D; $t$ test; percentage correct: $t_{(547)}=15.5, p<0.01$; movement time: $t_{(547)}=39.8, p<$ $0.01)$. Slower latencies resulted in STOP trial performance consistent with a speed accuracy trade off. This is illustrated in Figure $1 E$ which plots average movement times (well entry minus port exit) on STOP trials against percentage of correct STOP trials for all recording sessions. During sessions in which rats were slower, performance was better $(r=0.44 ; p<0.01)$. Consistent with this finding, movement times on STOP error trials were significantly 
faster than movement times on correctly performed STOP trials (Fig. $1 D ; \mathrm{t}_{(1016)}=20.64, p<0.01$ ). Combined, these results demonstrate that there is high conflict between two competing responses during STOP trials. That is, rats were planning and generating a movement before illumination of the STOP cue in response to the first cue light, and that inhibition and redirection of the behavioral response was necessary to correctly perform STOP trials. Trials during which the movement had to be stopped and redirected will be compared with responses made in the same ultimate direction, which cannot be accomplished with more typical stop-signal tasks that require subjects to either pause all movement or redirect toward a centralized food cup. This is important because the activity of neurons in rat OFC have been shown to be directionally selective (Feierstein et al., 2006; Roesch et al., 2006; Furuyashiki et al., 2008).

We recorded 548 OFC neurons from four rats over 112 sessions. The recording locations are illustrated in Figure $1 F$. We first assessed how many neurons significantly increased or decreased firing rate relative to baseline. The chosen epoch of analysis lasted from the time the rat withdrew from the nose-port until reaching the fluid well (response epoch), whereas the baseline epoch lasted $1 \mathrm{~s}$ beginning $2 \mathrm{~s}$ before nose-poke (trial initiation). In OFC, 209 (38\%) and 131 (24\%) neurons increased and decreased firing during the response epoch relative to baseline, respectively. The number of neurons that exhibited firing significantly different from baseline was more than expected from chance alone (increasing-type, $\chi^{2}=1260.25, p<0.01$; decreasing-type, $\left.\chi^{2}=409.64, p<0.01\right)$ and there were significantly more increasing-type compared with decreasing-type neurons $\left(\chi^{2}=17.85, p<0.01\right)$. Below we address how these populations of cells were modulated by trial-type (GO vs STOP), response direction, correctness, and movement speed.

\section{Increasing-type cells in OFC}

To qualify activity over the increasing-type neurons in OFC, we constructed population histograms that represent the average firing over time during execution of a trial. Because activity in OFC is often modulated by response direction, but not always the same direction, we segregated population activity into each cell's preferred and nonpreferred response directions. Preferred direction is defined as the movement direction that elicited the strongest firing during the response epoch, averaged over correct STOP and GO trials (always referred to the ultimate response direction performed, not the successfully inhibited direction). As defined by our analysis, activity in the preferred direction (Fig. $2 A, B$, thick solid lines) is always stronger than activity in the nonpreferred direction (Fig. 2A, B, thin solid lines) during the response epoch.

As described previously, increasing-type neurons in rat OFC are spatially selective (Feierstein et al., 2006; Roesch et al., 2006; Furuyashiki et al., 2008), firing more strongly for movements made in one direction over another. On correct GO (blue) trials, activity differentiated between the preferred (thick) and nonpreferred (thin) directions before withdrawal from the nose port. This can be observed via the tick marks in Figure $2 A$ that represent statistically significant ( $t$ test, $p<0.01$ ) directional activity (preferred vs nonpreferred directions) in $100 \mathrm{~ms}$ windows that slide every $10 \mathrm{~ms}$. This direction specificity on GO trials (blue ticks) suggests that the correct direction was encoded swiftly. On correct STOP trials (Fig. 2A,B), the correct direction was encoded after the rat exited the nose-port as can be observed by the red tick marks. The noticeable difference between STOP and GO trials is that the directional signal took longer to develop during
STOP trials. Neural activity for all trial types increased before port exit. On STOP trials in which rats had to inhibit responding to the cell's preferred direction and redirect behavior toward the nonpreferred direction (thin red) activity ceased firing shortly after the onset of the STOP cue and before the SCRT (234 ms; Fig. $2 A$, vertical dashed line). This relatively delayed directional encoding on STOP trials is consistent with longer movement times (Figs. 1D, 2A, red vs blue arrowheads).

Although we observed behavioral evidence of response conflict on STOP trials and directional signals took longer to develop, the strength of the directional signal during the entire response epoch was not significantly weaker on STOP relative to GO trials. This is illustrated in Figure 2C,D, which plots the distributions of directional indices (preferred-nonpreferred/preferred + nonpreferred) for both correct GO and STOP trials during the response epoch. Like above, we defined each cell's preference as the direction that showed the stronger response when averaging over the mean firing on STOP trials and the mean firing on GO trials. Thus, this analysis allows us to ask whether the distribution of directional indices, and therefore the strength of the directional signal, is different between the two trial-types across the population of increasing-type neurons. The same analysis performed on data from dorsal striatum (DS) neurons illustrated weaker directional signals on STOP trials (Bryden et al., 2012). Here, in OFC, the directional index distribution for both GO and STOP trialtypes (Fig. $2 A, B$, solid lines) was shifted significantly above zero (Fig. $2 C, D$; Wilcoxon, $p$ values $<0.01 ; \mu s=0.12,0.12$ ) and there was no difference between the two distributions (Fig. 2C,D; Wilcoxon, $p=0.84$ ), suggesting that even though the directional signal took longer to develop under STOP trials, it was resolved before the completion of the response as is evident in the neural activity aligned to well entry in Figure $2 \mathrm{~B}$. On STOP error trials (dashed lines), the directional signal during the response epoch was reduced implying that adequate encoding of direction in OFC was necessary for correct performance. On STOP error trials, the mean of the distribution of directional indices was significantly lower compared with correct STOP trials (Fig. 2D,E; Wilcoxon, $p<0.05$ ).

Overall these results suggest that when the directional signal is not fully reconciled on STOP trials, rats tend to make mistakes. This implies that the strength of the directional signal is directly tied to the motor output of the animal; thus, when it is weak, the correct direction is not discerned and errors are made. Therefore the strength of the directional signal might also be related to the speed of the response on correct trials (Feierstein et al., 2006). When rats are fast and correct, one might expect that the directional signal was strong (i.e., large difference), whereas when rats were slow, the directional signal might have been weak or taken longer to accurately encode the correct response.

To test this hypothesis we divided trials into FAST and SLOW speeds based on a median split of movement times (latency between port exit and well entry) separately for both directions on correct STOP and GO trials, and replotted the histograms and distributions of direction indices (average movement times: FAST GO $=429 \mathrm{~ms}$, FAST STOP $=646 \mathrm{~ms}$, SLOW GO $=721$ $\mathrm{ms}$, SLOW STOP $=987 \mathrm{~ms}$; Fig. $3 A-D)$. Notably, FAST and SLOW movement times were accompanied by longer and shorter reaction times (as defined by the latency to leave the central port; $t$ test, $p<0.01$ ), respectively. Consistent with the hypothesis laid out above, directional signals took longer to develop (Fig. $3 A, B$ ) and the shift in the distribution of directional indices was significantly stronger during FAST compared with SLOW STOP trials (Fig. $3 C$, right, $D$, right; Wilcoxon; $p<0.01$ ). 


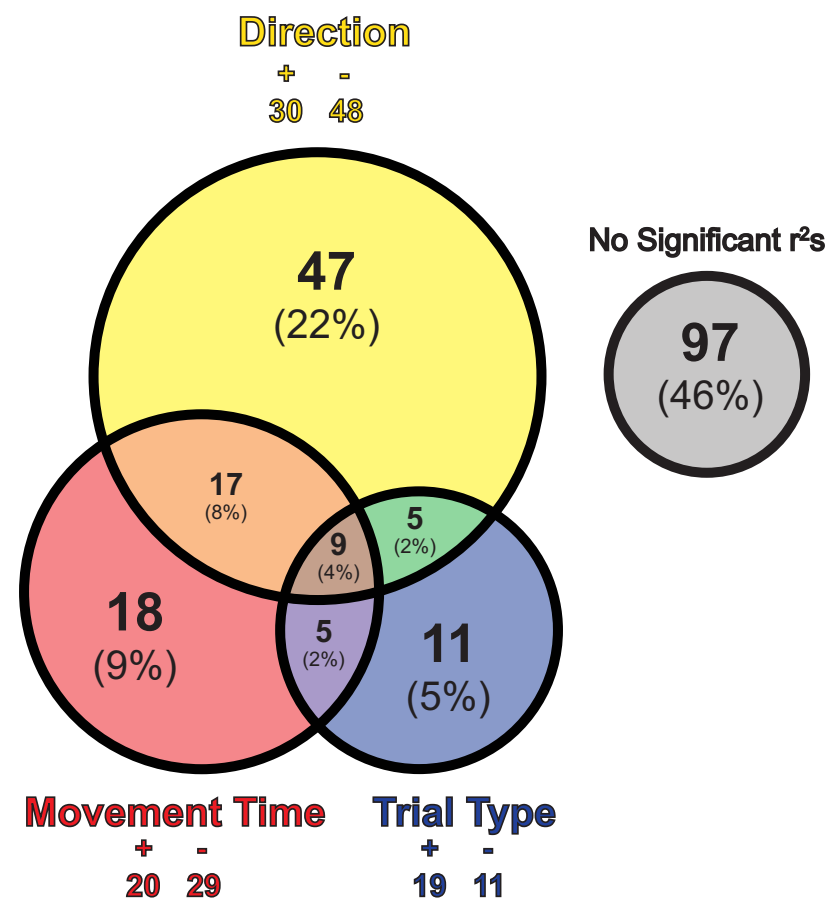

Figure 4. Multiple regression analysis for individual increasing-type neurons. The yellow circle denotes the number (and percentage) of increasing-type OFC cells that showed a significant partial $r^{2}$ value for the direction parameter. Analysis details in the Materials and Methods section. The red circle displays the number (and percentage) of OFC increasing-type cells showing a significant partial $r^{2}$ value for the movement time parameter. The blue circle reveals the number (and percentage) of OFC increasing-type cells that show significant partial $r^{2}$ values for the trial-type (i.e., STOP vs GO) parameter. " +" and " - " values signify the number of cells within a given parameter that show associated positive or negative $\beta$ values, respectively. Asterisks represent that the number of positive and negative $\beta$ values for a given parameter are significantly different from $50 / 50$ chance (binomial sign test, $p<0.05$ ). Overlapping portions represent the number of cells where two (orange, green, purple) or three (brown) parameters show significant partial $r^{2}$ values. Sizes of individual circles and overlapping portions are proportional to the percentage of neurons showing their respective effects. The gray circle represents the number (and percentage) of OFC increasing-type neurons where neither direction, movement time, nor trial-type exhibited significant partial $r^{2}$ values.

To determine whether neuronal firing correlates with movement speed, direction, and/or type of trial at the single-cell level, we performed the multiple regression procedure described in Materials and Methods. The top circle in Figure 4 indicates the number and percentage of increasing-type OFC cells that were significantly modulated by the direction of the response when variance for the other parameters was accounted for (partial $r^{2}$ ). Thirty-seven percent of increasing-type neurons $(n=78)$ were significantly modulated by direction and of these 78 neurons, 48 $\beta$ values of the direction parameter were negative (greater firing for the ipsilateral direction), whereas 30 were positive (binomial sign test, $p=0.05)$. Forty-nine cells $(23 \%)$ were significantly modulated by movement time (Fig. 4; movement time). Of these 49 , equal numbers showed positive and negative $\beta$ values for the movement time parameter ( 20 vs 29 ; binomial sign test, $p=$ $0.25)$. In 26 neurons, both the direction and movement speed parameters showed significant partial $r^{2}$ values (Fig. 4, orange + brown). Thus, consistent with the population analysis described above, OFC neurons encoded both response direction and movement speed.

Clearly signals in OFC are related to motor output and response direction. However, from these results it appears that OFC does not encode a pure response inhibition signal which one might predict to be independent of response direction (Schmidt et al., 2013). At the population-level, activity was not significantly different on a simple GO versus STOP trial comparison ( $t$ test, $p=0.60)$ for increasing-type neurons. At the single cell level, 30 neurons (14\%) showed significant partial $r^{2}$ values in our regression procedure (Fig. 4; trial-type), but only 11 of those neurons, $5 \%$ of the population of increasing-type neurons, showed a significant partial $r^{2}$ independent of significant modulation by direction and movement speed factors; a number not significantly different from chance $\left(\chi^{2}=0.03, p=0.86\right)$.

\section{Decreasing-type cells in OFC}

Of the 548 neurons recorded in OFC, 131 (24\%) fired significantly less during the response epoch compared with baseline. We performed identical analyses on decreasing-type cells as for the increasing-type neurons described above.

Population firing for decreasing-type neurons exhibited subtle modulation by response direction (i.e., preferred vs nonpreferred) with little modulation by trial-type (Fig. $5 A, B$, solid lines). This minimal directional effect is apparent when observing the tick marks in Figure $5 A$ which represent the significant difference ( $t$ test, $p<0.01$ ) between the preferred and nonpreferred directions during sliding $100 \mathrm{~ms}$ epochs for correct GO trials (blue ticks) and correct STOP trials (red ticks). Consistent with this observation, direction index distributions for both preferred and nonpreferred directions were significantly shifted above zero for correct GO and STOP trial-types (Fig. 5C,D; Wilcoxon; $p$ values $<0.01$ ) and not significantly different from one another (Fig. 5C,D; Wilcoxon, $p=0.84$ ). Thus, decreasing-type OFC neurons also appear to signal direction related responses when inhibition and redirection of behavior is necessary. To further support this assertion, we analyzed errant STOP trials and found that activity during these trials was not modulated by response direction as indicated by a nonsignificant shift in the directional index distribution (Fig. $5 E$; Wilcoxon, $p=0.59$ ). Importantly, the direction distribution for STOP errors was significantly reduced relative to correct STOP trials (Fig. 5D,E; Wilcoxon, $p<$ 0.01 ). This lack of directionality on STOP errors suggests that when animals fail to inhibit and redirect their response, the activity involved in directional responding does not reliably distinguish between the two actions.

To infer the extent to which OFC decreasing-type neurons are modulated by movement speed, we divided trials into FAST and SLOW movement speeds via median split (average movement times: FAST GO $=420 \mathrm{~ms}$, FAST STOP $=633 \mathrm{~ms}$, SLOW GO = $720 \mathrm{~ms}$, SLOW STOP = $972 \mathrm{~ms}$; Fig. 6A-D). As in the increasingtype population, SLOW movement speeds coincided with shorter reaction time (cue to unpoke) latencies when compared with reaction times in FAST movement trials ( $t$ test, $p<0.01$ ).

Unlike increasing-type neurons, average activity (for all trialtypes) was reduced in decreasing-type neurons when rats were FAST compared with when they were SLOW ( $t$ test, $p<0.01$ ). However, like increasing-type neurons, directional signals on STOP trials were significantly stronger when rats were FAST versus when they were SLOW (Fig. $6 C$, right, $D$, right; Wilcoxon, $p<$ 0.01 ) and there was a trend toward greater directional signals when rats were faster on GO trials (Fig. $6 C$, left, $D$, left; Wilcoxon, $p=0.14)$

In the multiple regression analysis, 31 neurons (24\%) were significantly modulated by movement time (Fig. 7; movement time). Significantly more of these neurons $(n=25)$ showed positive $\beta$ values (i.e., greater firing for slower movement) than negative $\beta$ values $(n=6$; binomial sign test, $p<0.01$ ). Of these 31 
A

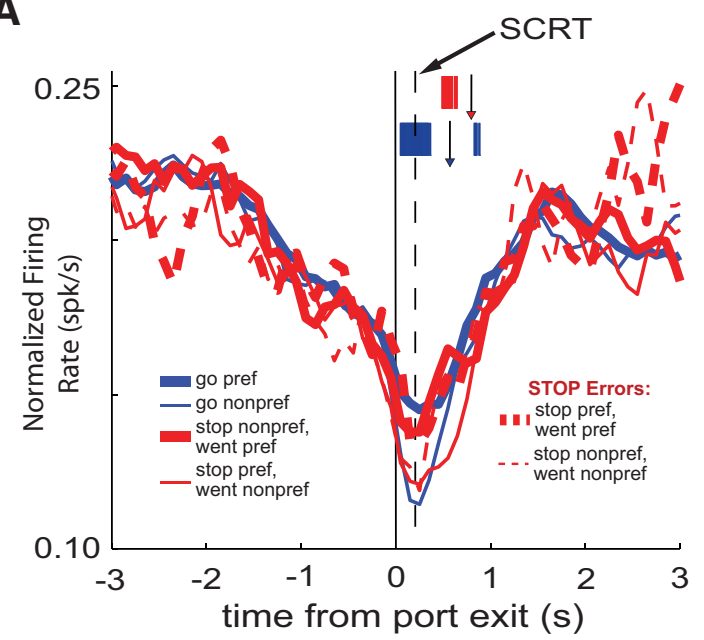

B

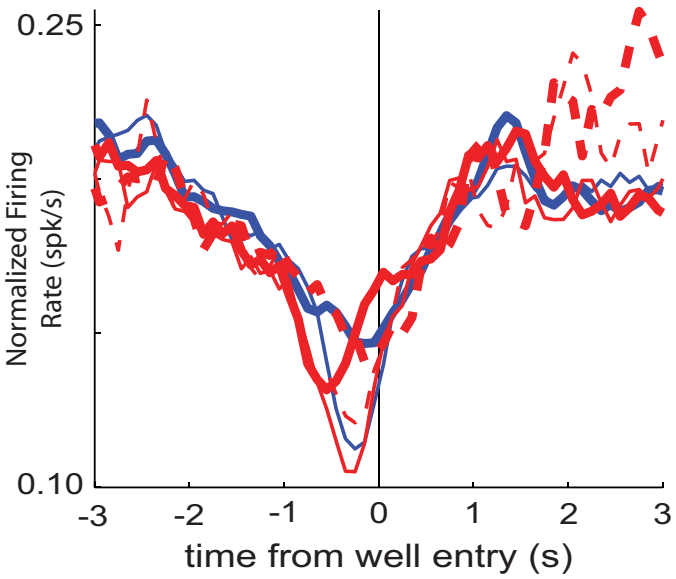

*

*
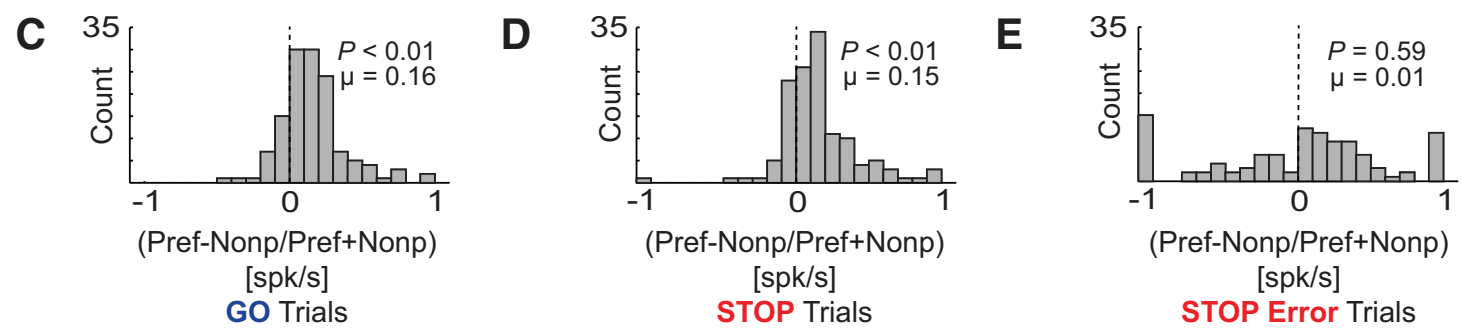

Figure 5. Impact of direction and trial-type on decreasing-type OFC neurons. $\boldsymbol{A}, \boldsymbol{B}$, Population histograms of all OFC neurons that fired significantly below baseline ( $n=131$ ). Average SCRT (vertical dashed line) is $224 \mathrm{~ms}$. Average movement times were $793 \mathrm{~ms}$ on STOP trials (red arrowhead) and 569 ms on G0 trials (blue arrowhead). Other conventions as in Figure 2 . $\mathbf{C}-\boldsymbol{E}$, All conventions as in Figure 2.

neurons, eight of them were also modulated by direction (Fig. 7, orange). Twenty neurons $(15 \%)$ were only modulated by the direction parameter (Fig. 7; direction). Last, trial-type yielded only five neurons (4\%) that exhibited significant partial $r^{2}$ values (Fig. 7; trial-type). Thus, like increasing-type neurons, activity of decreasing-type neurons was closely tied the direction and speed of behavior, rather than the need to inhibit action.

\section{Conflict-induced executive control of directional signals in OFC}

Although our task was designed to study the role of response inhibition on single cells, the swift and continuous manner in which our rats completed trials in addition to the random sequence of our trial types allows us to investigate the impact of immediate prior experience on activity. Behaviorally, using multiple tasks, it has been shown that efficient performance on the current trial is dependent on the degree of conflict on the previous trial (Carter and van Veen, 2007). The theory suggests that on a nonconflict trial preceded by a conflict trial, the subject should exhibit slower response times and higher control than in situations where the nonconflict trial is preceded by a nonconflict trial. Additionally, on a conflict trial preceded by a nonconflict trial, the competing irrelevant response should have a larger impact on the ultimate response and therefore increase response latencies relative to when a conflict trial is preceded by a conflict trial. These behavioral findings have been referred to as the "conflict adaptation effect" (Botvinick et al., 2001; Mayr et al., 2003).
Consistent with conflict adaptation, rats in our task were faster on correct STOP trials following STOP (i.e., conflict) trials relative to those that followed GO (i.e., no conflict) trials (Fig. $8 \mathrm{~A}$, green vs red arrowheads; $t$ test, $p<0.01)$. Additionally, movement times were faster on correct GO trials following GO trials than they were on correct GO trials following STOP trials (Fig. $8 C$, green vs red arrowheads; $t$ test, $p<0.01$ ).

So far we have shown that directional signals on STOP trials are fairly resilient to the competition between two conflicting responses, demonstrating the OFC is accurately signaling the correct direction during response inhibition. Here, we ask whether directional tuning in OFC might actually be enhanced during conflict adaption, when executive control is more engaged due to trial sequence. To address this issue, we plotted average firing of increasing-type cells broken down by STOP trials that were preceded by either a GO (Fig. $8 A$, red lines) or a STOP (Fig. $8 A$, green lines) trial. Quite strikingly, direction signals on correct STOP trials following STOP trials were greater than on correct STOP trials following GO trials. This observation is statistically validated in Figure $8 B$ which shows that the distribution of direction indices was greater on STOP trials following STOP trials relative to STOP trials following GO trials (Fig. 8 middle, right; Wilcoxon; $p<0.01$ ) and relative to direction signals on all correct GO trials (Fig. $8 A$, blue lines, $B$ left, right; Wilcoxon, $p<0.05$ ). Notably, this effect was not dependent on whether the previous trial was correct or an error; the directional signal on correct STOP trials following correct and incorrect STOP trials was not significantly different (Wilcoxon; $p=0.17$ ). 
A

FAST Movement Times

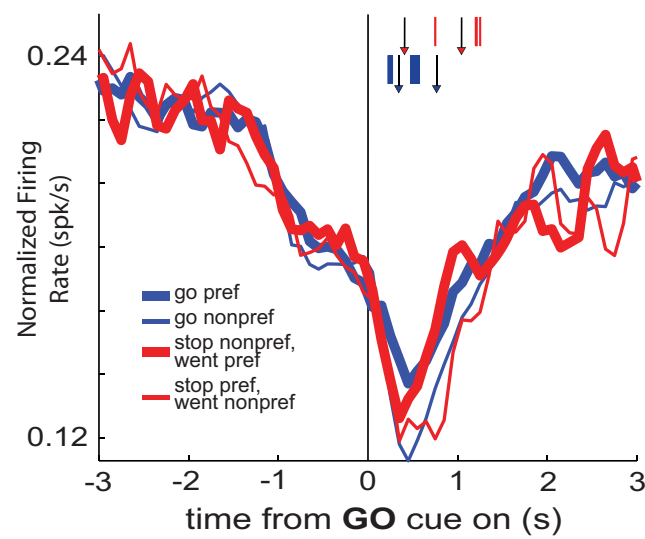

C

FAST Movement Times
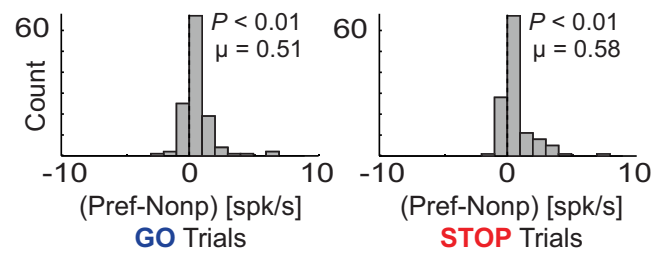

B

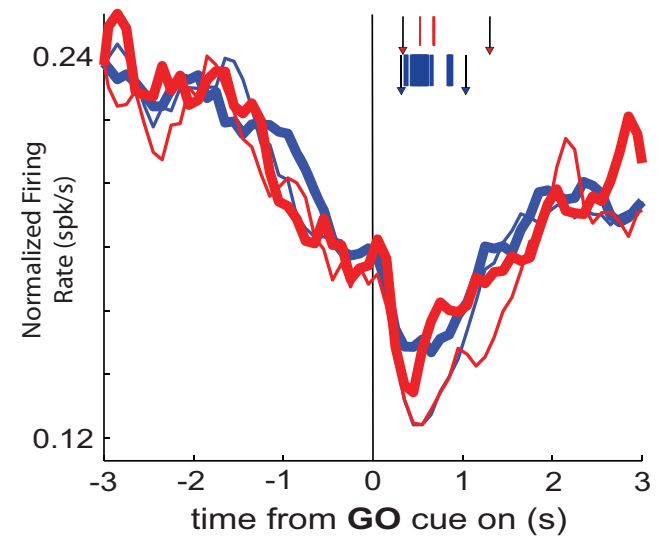

D

SLOW Movement Times
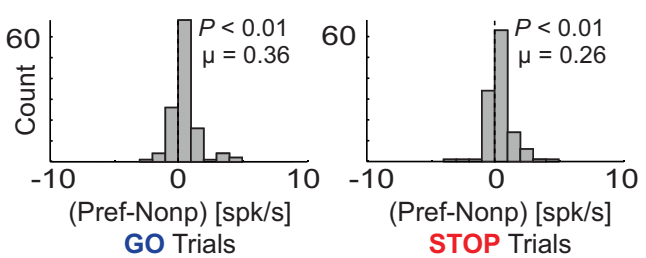

Figure 6. Firing of decreasing-type OFC neurons was related to movement time. $\boldsymbol{A}, \boldsymbol{B}$, Population histograms of all decreasing-type $0 \mathrm{FC}$ neurons ( $n=131$ ). Tick marks represent time points of statistically significant direction firing (preferred vs nonpreferred direction) for $\mathrm{G} 0$ trials (blue) or STOP trials (red) analyzed by sliding a $100 \mathrm{~ms}$ window every $10 \mathrm{~ms}$ ( $t$ test, $p<0.01$ ). Left-most arrows depict average latency to unpoke after G0 cue illumination for STOP trials (red arrowheads; FAST $=407 \mathrm{~ms} ; \mathrm{SLOW}=338 \mathrm{~ms}$ ) and G0 trials (blue arrowheads; FAST $=344 \mathrm{~ms} ; \mathrm{SLOW}=322$ ms) for the analyzed sessions. Right-most arrows depict average latency to well entry after G0 cue illumination for STOP trials (red arrowheads; FAST = 1041 ms; SLOW = 1310 ms) and G0 trials (blue arrowheads; FAST $=764 \mathrm{~ms} ;$ SLOW $=1042 \mathrm{~ms}$ ) for the analyzed sessions. Other conventions as in Figure 3. C, D, All conventions as in Figure 3.

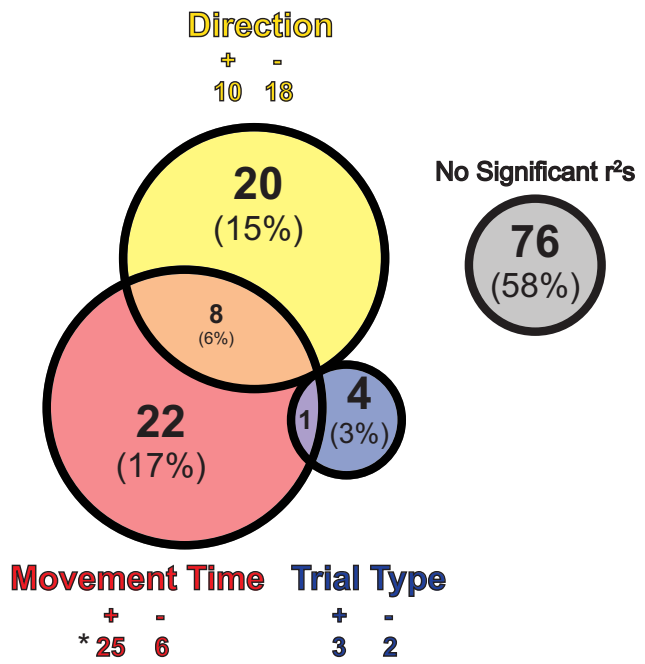

Figure 7. Multiple regression analysis for individual decreasing-type neurons. Conventions as in Figure 4 for decreasing-type neurons.

Importantly, this effect was dependent on the current trial being a STOP trial, suggesting that directional signals were enhanced only when it was needed to inhibit and redirect behavior. This is illustrated in Figure $8 C, D$, which examines the impact of the previous trial on GO trials. Directional signals on correct GO trials was not significantly modulated by the identity of the previous trial (i.e., STOP or GO; Fig. 8D, left, right; Wilcoxon, $p=0.99$ ).

\section{Directional signals in OFC are negatively correlated with performance}

Last, we asked whether directional signals in OFC were correlated with task performance. We hypothesized the OFC is most critical during sessions when rats were performing worse at that task. During these sessions, rats would require additional conflictinduced executive control to cope with conflicting responses. To determine the relationship between these directional signals and performance, we plotted the difference between activity during the response epoch on preferred and nonpreferred directions (direction signal) against accuracy on STOP trials. Remarkably, directional signals in increasing-type neurons tended to be stronger when rats were less accurate on STOP trials. The correlation between the two was significant and negative (Fig. $8 E ; p<0.05$, $r=-0.16$ ) suggesting that when rats had the most trouble inhibiting and redirecting behavior, directional signals in OFC were stronger. This implies that the OFC was critical for controlling direction-based behavior when the need to override prepotent habitual behavior was the greatest.

For decreasing-type neurons, this correlation was also negative, but not significant (Fig. $8 F ; p=0.22, r=-0.11$ ).

\section{Discussion}

Research has suggested that OFC acts as a frontal area integral for inhibitory control. Dysfunction in OFC has been critically implicated in many disorders that impact inhibitory control including addiction, Tourette syndrome, obsessive compulsive disorder, and attention deficit hyperactivity disorder (Schachar et al., 1995, 
A

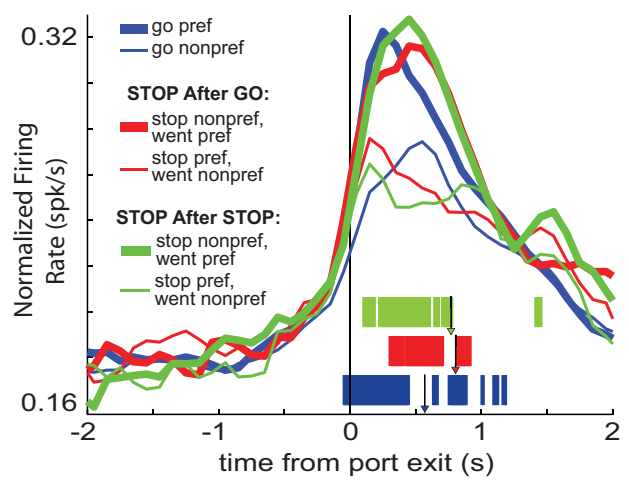

C

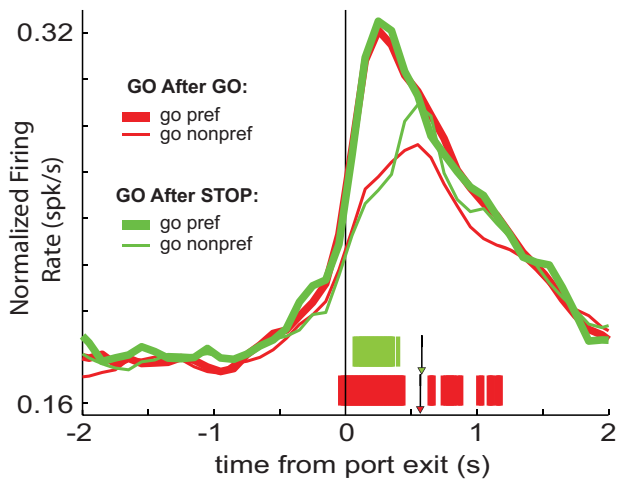

E
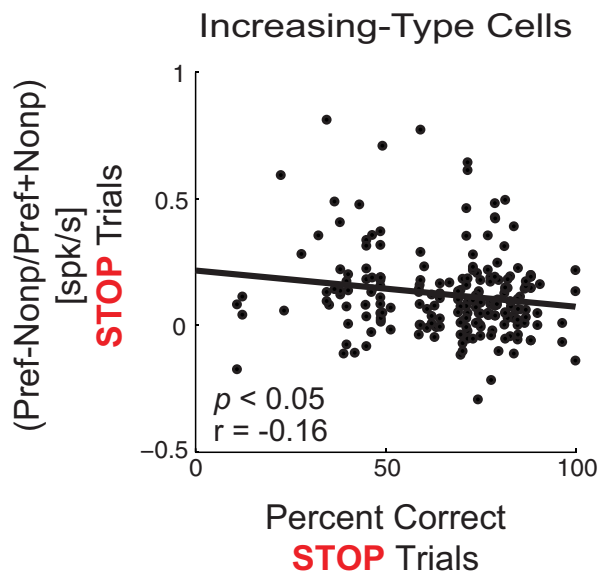

B

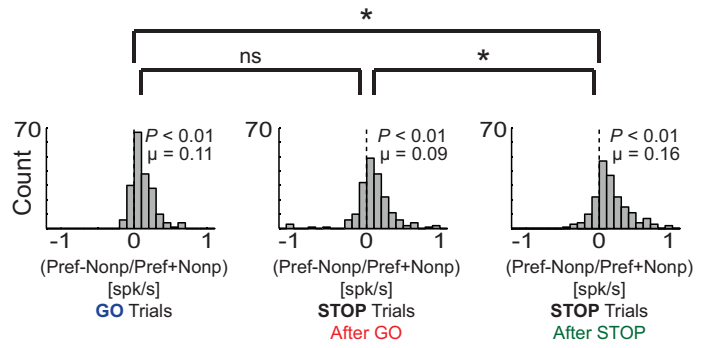

D

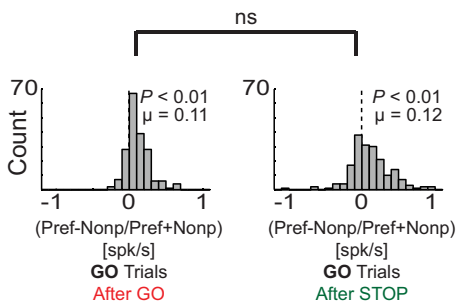

$\mathbf{F}$

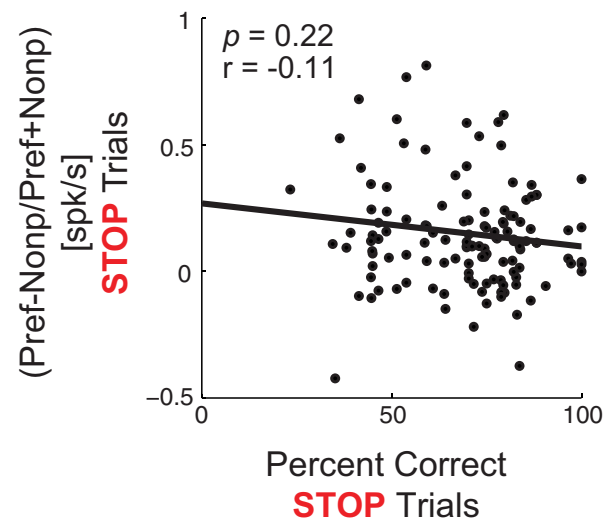

Figure 8. Strength of direction signals is modulated by presence of previous trial conflict. A, Population histogram of all OFC neurons that fired significantly above baseline $(n=209)$. Blue lines refer to all correct $\mathrm{GO}$ trials. Red lines refer to correct STOP trials where the previous trial was a GO trial. Green lines refer to correct STOP trials where the previous trial was a STOP trial. Tick marks represent time points of statistically significant direction firing (preferred vs nonpreferred direction) for GO trials (blue), STOP trials following GO trials (red), and STOP trials following STOP trials (green) analyzed by sliding a $100 \mathrm{~ms}$ window every $10 \mathrm{~ms}$ ( $t$ test, $p<0.01$ ). Individual arrows depict average movement time for $\mathrm{G} 0$ trials (blue arrowhead; $570 \mathrm{~ms}$ ), STOP trials following G0 trials (red arrowhead; $804 \mathrm{~ms}$ ) and STOP trials following STOP trials (green arrowhead; $770 \mathrm{~ms}$ ) for the analyzed sessions. All other conventions as in Figure 2. B, Direction index distributions for correct GO trials (left), correct STOP trials following GO trials (middle), and correct STOP trials following STOP trials (right). All other conventions as in Figure 2. C, Population histogram of all OFC neurons that fired significantly above baseline $(n=209)$, where red lines refer to correct $G 0$ trials following $G 0$ trials and green lines refer to correct $G 0$ trials following STOP trials. Individual arrows depict average movement time for $\mathrm{GO}$ trials following $\mathrm{G} 0$ trials (red arrowhead; $568 \mathrm{~ms}$ ) and $\mathrm{GO}$ trials following STOP trials (green arrowhead; $580 \mathrm{~ms}$ ) for the analyzed sessions. $\boldsymbol{D}$, Direction index distributions for GO trials following GO trials (left) and GO trials following STOP trials (right). Other conventions as in B. E, F, Correlations between direction signal strength (preferred - nonpreferred/preferred + nonpreferred) on STOP trials and the percentage of correct STOP trials in increasing- $(\boldsymbol{E})$ and decreasing-type cells $(\boldsymbol{F})$.

2007; Weeks et al., 1996; Oosterlaan and Sergeant, 1998; Oosterlaan et al., 1998; Rubia et al., 1998, 2005, 2007; Fillmore and Rush, 2002; Gauggel et al., 2004; Aron and Poldrack, 2005; Kalanithi et al., 2005; Monterosso et al., 2005; Nigg et al., 2005; Bellgrove et al., 2006; Fillmore et al., 2006; Makris et al., 2007; Durston et al., 2009; Eagle and Baunez, 2010; Kataoka et al., 2010; Leventhal et al., 2012). In fact, recent work has demonstrated that optogenetic stimulation of lateral OFC and its terminals in striatum can re- store normal levels of response inhibition in a mouse model of compulsive behavior (Burguière et al., 2013) and pharmacological manipulation of this brain area in rats has been suggested to disrupt stopping with striking parallels to observations made in inferior frontal cortex in humans (Aron et al., 2014).

Although this previous work suggests that OFC provides a type of inhibitory signal that can aid in response suppression, others have strongly refuted this theory arguing that rats with 
impaired OFC function can still perform a number of tasks that require response inhibition. Furthermore, a barrage of singleunit studies over the past few years have suggested that neural activity in OFC better reflects expectations about future outcomes critical for reward-guided decision-making tasks that do not necessarily involve response inhibition (Schultz et al., 2000; Wallis, 2007; Schoenbaum et al., 2009; Padoa-Schioppa, 2011; Moorman and Aston-Jones, 2014). Decreased function after OFC lesions in tasks such as reversal and reinforcer devaluation can be parsimoniously explained by reward expectancy encoding rather than a decrement in the capacity to inhibit behavior.

Considering the debate on OFC's role in response inhibition, it comes as a surprise that no one has recorded from OFC in a task that requires response inhibition independent from manipulations of expected outcomes. We chose to examine neural correlates during performance of a stop-signal task for several reasons. First, stop-signal performance is disrupted in a number of psychiatric disorders that are thought to impact function of the OFC circuit (Weeks et al., 1996; Aron and Poldrack, 2005; Rubia et al., 2005; Makris et al., 2007; Durston et al., 2009; Eagle and Baunez, 2010). Second, imaging studies clearly suggest higher firing on stop relative to go trials in OFC in several tasks including ones that require suppression of specific response types (e.g., left/right; Rubia et al., 2005; Chikazoe et al., 2009; Majid et al., 2013). The third reason we chose a stop-signal task is that pharmacological studies suggest that OFC is critical for normal stop-signal performance. Lesions disrupt performance on stop-signal tasks and administration of atomoxetine (ADHD drug) into OFC improves stop-signal performance (Bari et al., 2011). Although these studies do not "require" rats to redirect movement on STOP trials, rats do redirect their ongoing movement away from the habitual response directly to the food cup to receive reward. From these studies, it is clear that during performance of stopsignal tasks, OFC is critical for inhibition of movement on stop trials and that when subjects successfully suppress behavior, activity in OFC appears to be elevated.

Here, we recorded from OFC in our variant of the classic stop-signal task. On STOP trials, which occurred on $20 \%$ of trials, rats had to inhibit their directional response and redirect behavior to the opposite location. By having rats redirect behavior, we can compare activity on STOP and GO trials when the same ultimate movement is made. Rats were slower and performed more poorly on STOP trials relative to simple GO trials. Further, rats were significantly faster on STOP errors demonstrating that errors occurred because rats were rapidly planning their response in the wrong direction, and therefore needed to inhibit the movement to perform STOP trials (Schmidt et al., 2013). Thus, use of this task in the context of behavioral neurophysiology allows for direct comparison of responses made in the same direction in the presence and absence of response suppression because rats had to make a response on every trial to receive reward. This approach cannot be taken with more typical stop-signal tasks or other tasks that probe response inhibition (e.g., Go-NoGo, reversal).

The finding that BOLD signal is increased in OFC during response suppression can be interpreted in several different ways. On one hand, increased signal on stop relative to go trials might arise from neurons that signal the need for response inhibition. That is, single neurons in OFC elevate firing whenever subjects are required to suppress an ongoing movement. On the other hand, increased BOLD signal may arise from neurons active in conjunction with planning different actions. Similar to the argument originally posited by Nakamura and colleagues, on stop trials, there is simultaneous activation of neurons signaling the movement that needs to be stopped and the one necessary for accurate performance (Nakamura et al., 2005). Thus, the net activity of this population of neurons might increase during response inhibition because neurons that signal for opposing actions will be simultaneously active.

Our results are more consistent with the second explanation. Overall, we found that activity in OFC does not appear to carry a pure inhibitory signal. Population firing in OFC was not significantly stronger under STOP trials, nor were there a preponderance of single neurons that fired significantly more strongly on STOP over GO trials. Instead we found that OFC neurons exhibited directional tuning as previously reported (Feierstein et al., 2006; Roesch et al., 2006; Furuyashiki et al., 2008), and that directional selectivity was enhanced by the need to suppress and redirect behavior, especially during sequences of increased conflict resolution. This interpretation is broadly consistent with recent work in monkeys suggesting that OFC is involved in reconciling cognitive signals during conflict adaptation (Mansouri et al., 2014).

All of this suggests that OFC is more involved in executive functions that control and enhance response selectivity when unwanted movements are suppressed and redirected. We suspect that this signal is critical for resolving conflict observed in neural signals downstream of OFC, such as DS (Bryden et al., 2012). Dysfunction of these correlates can explain why interference of OFC function impairs response inhibition. Although the most obvious interpretation is that OFC provides some sort of inhibition signal, our results suggest that OFC plays an important role in conflict-induced executive control (Mansouri et al., 2014). Such a function might be critical for performance on several tasks that require inhibition and are impaired after OFC lesions, including reversal learning (Butter, 1969), delay discounting (Mobini et al., 2002), extinction (Bouton, 2004), delayed alternation (Mishkin et al., 1969), and devaluation (Pickens et al., 2003).

\section{References}

Aron AR, Poldrack RA (2005) The cognitive neuroscience of response inhibition: relevance for genetic research in attention-deficit/hyperactivity disorder. Biol Psychiatry 57:1285-1292. CrossRef Medline

Aron AR, Robbins TW, Poldrack RA (2014) Inhibition and the right inferior frontal cortex: one decade on. Trends Cogn Sci 18:177-185. CrossRef Medline

Bari A, Mar AC, Theobald DE, Elands SA, Oganya KC, Eagle DM, Robbins TW (2011) Prefrontal and monoaminergic contributions to stop-signal task performance in rats. J Neurosci 31:9254-9263. CrossRef Medline

Bechara A, Damasio H, Damasio AR, Lee GP (1999) Different contributions of the human amygdala and ventromedial prefrontal cortex to decisionmaking. J Neurosci 19:5473-5481. Medline

Bellgrove MA, Chambers CD, Vance A, Hall N, Karamitsios M, Bradshaw JL (2006) Lateralized deficit of response inhibition in early-onset schizophrenia. Psychol Med 36:495-505. Medline

Bissonette GB, Martins GJ, Franz TM, Harper ES, Schoenbaum G, Powell EM (2008) Double dissociation of the effects of medial and orbital prefrontal cortical lesions on attentional and affective shifts in mice. J Neurosci 28:11124-11130. CrossRef Medline

Botvinick MM, Braver TS, Barch DM, Carter CS, Cohen JD (2001) Conflict monitoring and cognitive control. Psychol Rev 108:624-652. CrossRef Medline

Bouton ME (2004) Context and behavioral processes in extinction. Learn Mem 11:485-494. CrossRef Medline

Bryden DW, Johnson EE, Diao X, Roesch MR (2011) Impact of expected value on neural activity in rat substantia nigra pars reticulata. Eur J Neurosci 33:2308-2317. CrossRef Medline

Bryden DW, Burton AC, Kashtelyan V, Barnett BR, Roesch MR (2012) Response inhibition signals and miscoding of direction in dorsomedial striatum. Front Integr Neurosci 6:69. CrossRef Medline

Burguière E, Monteiro P, Feng G, Graybiel AM (2013) Optogenetic stimu- 
lation of lateral orbitofronto-striatal pathway suppresses compulsive behaviors. Science 340:1243-1246. CrossRef Medline

Burton AC, Kashtelyan V, Bryden DW, Roesch MR (2014) Increased firing to cues that predict low-value reward in the medial orbitofrontal cortex. Cereb Cortex 24: 3310-3321. CrossRef Medline

Butter CM (1969) Perseveration in extinction and in discrimination reversal tasks following selective frontal ablations in Macaca mulatta. Physiol Behav 4:163. CrossRef

Carter CS, van Veen V (2007) Anterior cingulate cortex and conflict detection: an update of theory and data. Cogn Affect Behav Neurosci 7:367379. CrossRef Medline

Casey BJ, Trainor RJ, Orendi JL, Schubert AB, Nystrom LE, Giedd JN, Castellanos FX, Haxby JV, Noll DC, Cohen JD, Forman SD, Dahl RE, Rapoport JL (1997) A developmental functional MRI study of prefrontal activation during performance of a go-no-go task. J Cogn Neurosci 9:835-847. CrossRef Medline

Charles MB (1969) Perseveration in extinction and in discrimination reversal tasks following selective frontal ablations in Macaca mulatta. Physiol Behav 4:9.

Chikazoe J, Jimura K, Hirose S, Yamashita K, Miyashita Y, Konishi S (2009) Preparation to inhibit a response complements response inhibition during performance of a stop-signal task. J Neurosci 29:15870-15877. CrossRef Medline

Chudasama Y, Robbins TW (2003) Dissociable contributions of the orbitofrontal and infralimbic cortex to Pavlovian autoshaping and discrimination reversal learning: further evidence for the functional heterogeneity of the rodent frontal cortex. J Neurosci 23:8771-8780. Medline

Chudasama Y, Kralik JD, Murray EA (2007) Rhesus monkeys with orbital prefrontal cortex lesions can learn to inhibit prepotent responses in the reversed reward contingency task. Cereb Cortex 17:1154-1159. CrossRef Medline

Durston S, de Zeeuw P, Staal WG (2009) Imaging genetics in ADHD: a focus on cognitive control. Neurosci Biobehav Rev 33:674-689. CrossRef Medline

Eagle DM, Baunez C (2010) Is there an inhibitory-response-control system in the rat? Evidence from anatomical and pharmacological studies of behavioral inhibition. Neurosci Biobehav Rev 34:50-72. CrossRef Medline

Eagle DM, Baunez C, Hutcheson DM, Lehmann O, Shah AP, Robbins TW (2008) Stop-signal reaction-time task performance: role of prefrontal cortex and subthalamic nucleus. Cereb Cortex 18:178-188. CrossRef Medline

Feierstein CE, Quirk MC, Uchida N, Sosulski DL, Mainen ZF (2006) Representation of spatial goals in rat orbitofrontal cortex. Neuron 51:495507. CrossRef Medline

Fellows LK, Farah MJ (2003) Ventromedial frontal cortex mediates affective shifting in humans: evidence from a reversal learning paradigm. Brain 126:1830-1837. CrossRef Medline

Fillmore MT, Rush CR (2002) Impaired inhibitory control of behavior in chronic cocaine users. Drug Alcohol Depend 66:265-273. CrossRef Medline

Fillmore MT, Rush CR, Hays L (2006) Acute effects of cocaine in two models of inhibitory control: implications of non-linear dose effects. Addiction 101:1323-1332. CrossRef Medline

Furuyashiki T, Holland PC, Gallagher M (2008) Rat orbitofrontal cortex separately encodes response and outcome information during performance of goal-directed behavior. J Neurosci 28:5127-5138. CrossRef Medline

Gauggel S, Rieger M, Feghoff TA (2004) Inhibition of ongoing responses in patients with Parkinson's disease. J Neurol Neurosurg Psychiatry 75:539544. CrossRef Medline

Ghods-Sharifi S, Haluk DM, Floresco SB (2008) Differential effects of inactivation of the orbitofrontal cortex on strategy set-shifting and reversal learning. Neurobiol Learn Mem 89:567-573. CrossRef Medline

Hornak J, O’Doherty J, Bramham J, Rolls ET, Morris RG, Bullock PR, Polkey CE (2004) Reward-related reversal learning after surgical excisions in orbito-frontal or dorsolateral prefrontal cortex in humans. J Cogn Neurosci 16:463-478. CrossRef Medline

Horn NR, Dolan M, Elliott R, Deakin JF, Woodruff PW (2003) Response inhibition and impulsivity: an fMRI study. Neuropsychologia 41:19591966. CrossRef Medline

Iversen SD, Mishkin M (1970) Perseverative interference in monkeys fol- lowing selective lesions of the inferior prefrontal convexity. Exp Brain Res 11:376-386. Medline

Izquierdo A, Suda RK, Murray EA (2004) Bilateral orbital prefrontal cortex lesions in rhesus monkeys disrupt choices guided by both reward value and reward contingency. J Neurosci 24:7540-7548. CrossRef Medline

Jones B, Mishkin M (1972) Limbic lesions and the problem of stimulusreinforcement associations. Exp Neurol 36:362-377. CrossRef Medline

Kalanithi PS, Zheng W, Kataoka Y, DiFiglia M, Grantz H, Saper CB, Schwartz ML, Leckman JF, Vaccarino FM (2005) Altered parvalbumin-positive neuron distribution in basal ganglia of individuals with Tourette syndrome. Proc Natl Acad Sci U S A 102:13307-13312. CrossRef Medline

Kataoka Y, Kalanithi PS, Grantz H, Schwartz ML, Saper C, Leckman JF, Vaccarino FM (2010) Decreased number of parvalbumin and cholinergic interneurons in the striatum of individuals with Tourette syndrome. J Comp Neurol 518:277-291. CrossRef Medline

Kheramin S, Body S, Ho M, Velázquez-Martinez DN, Bradshaw CM, Szabadi E, Deakin JF, Anderson IM (2003) Role of the orbital prefrontal cortex in choice between delayed and uncertain reinforcers: a quantitative analysis. Behav Processes 64:239-250. CrossRef Medline

Leventhal DK, Gage GJ, Schmidt R, Pettibone JR, Case AC, Berke JD (2012) Basal ganglia beta oscillations accompany cue utilization. Neuron 73:523536. CrossRef Medline

Majid DS, Cai W, Corey-Bloom J, Aron AR (2013) Proactive selective response suppression is implemented via the basal ganglia. J Neurosci 33: 13259-13269. CrossRef Medline

Makris N, Biederman J, Valera EM, Bush G, Kaiser J, Kennedy DN, Caviness VS, Faraone SV, Seidman LJ (2007) Cortical thinning of the attention and executive function networks in adults with attention-deficit/hyperactivity disorder. Cereb Cortex 17:1364-1375. CrossRef Medline

Mansouri FA, Buckley MJ, Tanaka K (2014) The essential role of primate orbitofrontal cortex in conflict-induced executive control adjustment. J Neurosci 34:11016-11031. CrossRef Medline

Mayr U, Awh E, Laurey P (2003) Conflict adaptation effects in the absence of executive control. Nat Neurosci 6:450-452. CrossRef Medline

McAlonan K, Brown VJ (2003) Orbital prefrontal cortex mediates reversal learning and not attentional set shifting in the rat. Behav Brain Res 146: 97-103. CrossRef Medline

McEnaney KW, Butter CM (1969) Perseveration of responding and nonresponding in monkeys with orbital frontal ablations. J Comp Physiol Psychol 68:558-561. CrossRef Medline

Meunier M, Bachevalier J, Mishkin M (1997) Effects of orbital frontal and anterior cingulate lesions on object and spatial memory in rhesus monkeys. Neuropsychologia 35:999-1015. CrossRef Medline

Mishkin M, Vest B, Waxler M, Rosvold HE (1969) A re-examination of effects of frontal lesions on object alternation. Neuropsychologia 7:357-\&. CrossRef

Mobini S, Body S, Ho MY, Bradshaw CM, Szabadi E, Deakin JF, Anderson IM (2002) Effects of lesions of the orbitofrontal cortex on sensitivity to delayed and probabilistic reinforcement. Psychopharmacology (Berl) 160: 290-298. CrossRef Medline

Monterosso JR, Aron AR, Cordova X, Xu J, London ED (2005) Deficits in response inhibition associated with chronic methamphetamine abuse. Drug Alcohol Depend 79:273-277. CrossRef Medline

Moorman DE, Aston-Jones G (2014) Orbitofrontal cortical neurons encode expectation-driven initiation of reward-seeking. J Neurosci 34:1023410246. CrossRef Medline

Nakamura K, Roesch MR, Olson CR (2005) Neuronal activity in macaque SEF and ACC during performance of tasks involving conflict. J Neurophysiol 93:884-908. CrossRef Medline

Nigg JT, Silk KR, Stavro G, Miller T (2005) Disinhibition and borderline personality disorder. Dev Psychopathol 17:1129-1149. Medline

Oosterlaan J, Sergeant JA (1998) Response inhibition and response reengagement in attention-deficit/hyperactivity disorder, disruptive, anxious and normal children. Behav Brain Res 94:33-43. CrossRef Medline

Oosterlaan J, Logan GD, Sergeant JA (1998) Response inhibition in AD/ $\mathrm{HD}, \mathrm{CD}$, comorbid $\mathrm{AD} / \mathrm{HD}+\mathrm{CD}$, anxious, and control children: a metaanalysis of studies with the stop task. J Child Psychol Psychiatry 39:411425. CrossRef Medline

Padoa-Schioppa C (2011) Neurobiology of economic choice: a good-based model. Ann Rev Neurosci 34:333-359. CrossRef Medline

Pickens CL, Saddoris MP, Setlow B, Gallagher M, Holland PC, Schoenbaum G 
(2003) Different roles for orbitofrontal cortex and basolateral amygdala in a reinforcer devaluation task. J Neurosci 23:11078-11084. Medline

Roesch MR, Taylor AR, Schoenbaum G (2006) Encoding of timediscounted rewards in orbitofrontal cortex is independent of value representation. Neuron 51:509-520. CrossRef Medline

Rolls ET, Hornak J, Wade D, McGrath J (1994) Emotion-related learning in patients with social and emotional changes associated with frontal lobe damage. J Neurol Neurosurg Psychiatry 57:1518-1524. CrossRef Medline

Rubia K, Oosterlaan J, Sergeant JA, Brandeis D, v Leeuwen T (1998) Inhibitory dysfunction in hyperactive boys. Behav Brain Res 94:25-32. CrossRef Medline

Rubia K, Smith AB, Brammer MJ, Toone B, Taylor E (2005) Abnormal brain activation during inhibition and error detection in medicationnaive adolescents with ADHD. Am J Psychiatry 162:1067-1075. CrossRef Medline

Rubia K, Smith A, Taylor E (2007) Performance of children with attention deficit hyperactivity disorder (ADHD) on a test battery of impulsiveness. Child Neuropsychol 13:276-304. CrossRef Medline

Schachar R, Tannock R, Marriott M, Logan G (1995) Deficient inhibitory control in attention deficit hyperactivity disorder. J Abnorm Child Psychol 23:411-437. CrossRef Medline

Schachar R, Logan GD, Robaey P, Chen S, Ickowicz A, Barr C (2007) Restraint and cancellation: multiple inhibition deficits in attention deficit hyperactivity disorder. J Abnorm Child Psychol 35:229-238. CrossRef Medline

Schmidt R, Leventhal DK, Mallet N, Chen F, Berke JD (2013) Canceling actions involves a race between basal ganglia pathways. Nat Neurosci 16:1118-1124. CrossRef Medline
Schoenbaum G, Setlow B, Nugent SL, Saddoris MP, Gallagher M (2003) Lesions of orbitofrontal cortex and basolateral amygdala complex disrupt acquisition of odor-guided discriminations and reversals. Learn Mem 10:129-140. CrossRef Medline

Schoenbaum G, Roesch MR, Stalnaker TA, Takahashi YK (2009) A new perspective on the role of the orbitofrontal cortex in adaptive behaviour. Nat Rev Neurosci 10:885-892. CrossRef Medline

Schultz W, Tremblay L, Hollerman JR (2000) Reward processing in primate orbitofrontal cortex and basal ganglia. Cereb Cortex 10:272-284. CrossRef Medline

Swick D, Ashley V, Turken AU (2008) Left inferior frontal gyrus is critical for response inhibition. BMC Neurosci 9:102. CrossRef Medline

Wallis JD (2007) Neuronal mechanisms in prefrontal cortex underlying adaptive choice behavior. Ann N Y Acad Sci 1121:447-460. CrossRef Medline

Weeks RA, Turjanski N, Brooks DJ (1996) Tourette's syndrome: a disorder of cingulate and orbitofrontal function? QJM 89:401-408. CrossRef Medline

Winstanley CA, Theobald DE, Cardinal RN, Robbins TW (2004) Contrasting roles of basolateral amygdala and orbitofrontal cortex in impulsive choice. J Neurosci 24:4718-4722. CrossRef Medline

Zeeb FD, Winstanley CA (2011) Lesions of the basolateral amygdala and orbitofrontal cortex differentially affect acquisition and performance of a rodent gambling task. J Neurosci 31:2197-2204. CrossRef Medline

Zeeb FD, Floresco SB, Winstanley CA (2010) Contributions of the orbitofrontal cortex to impulsive choice: interactions with basal levels of impulsivity, dopamine signalling, and reward-related cues. Psychopharmacology 211:87-98. CrossRef Medline 